\title{
Contemplative Pedagogy and Mindfulness: Developing Creative Attention in an Age of Distraction
}

\section{AISLINN O'DONNELL}

Over the last decade, there has been a considerable expansion of mindfulness programmes into a number of different domains of contemporary life, such as corporations, schools, hospitals and even the military. Understanding the reasons for this phenomenon involves, I argue, reflecting upon the nature of contemporary capitalism and mapping the complexity of navigating new digital technologies that make multiple and accelerated solicitations upon attention and our affective lives. Whilst acknowledging the benefits of mindfulness practice, this article argues that it is equally important to attend to the ethical framework that gives orientation to these practices and the outer conditions that shape lived daily experience, such as school or work environments. I suggest that the well-meaning efforts to secularise mindfulness, provide scientific evidence for its effectiveness, and introduce it to wider publics may have served to impoverish the rich contribution that practices of mindfulness, situated within a broader ethical framework, can make to human lives, and arguably contribute to the educational endeavour. For example, the emphasis on transforming inner conditions of students' lives can lead to the neglect of outer conditions, such as structural inequality, or unhealthy and exploitative work practices. This can result in practices that privilege individual wellbeing over compassion and concern for the happiness of others, providing a buffer against loving attention to the world and others. Instead, I ask how mindfulness in educational settings could come to be viewed in a different light if we reflect upon the ways in which school environments and curricula can promote mindfulness, awareness, sensitive inquiry, and contemplative practices through the day, rather than offering it as a discrete intervention focused on the self and wellbeing. 


\section{INTRODUCTION: IS THERE A PROBLEM WITH MINDFULNESS?}

The introduction of mindfulness and meditation programmes across a wide range of institutions and organisations, including schools, is a welldocumented phenomenon. These programmes are sometimes seen to constitute another part of the array of what Bernard Stiegler calls psychotechnologies, as they too are concerned with the most intimate domain of our existence, our psychic lives, yet their relationship with capitalism and commodification has become a cause for concern. In light of this phenomenon, we might ask whether mindfulness has been co-opted as a coping technique in a world of information and sensory overload, and if so, what does it mean for students encountering mindfulness in schools. Critics argue that: mindfulness has been uprooted from rich wisdom traditions and has thus lost sight of its ethical orientation becoming a programmatic rather than pedagogical practice; it is simply another element in a very profitable self-help industry; or that when uncoupled from an ethical framework and philosophical investigation, it engages solely with symptoms rather than causes of suffering. Given the increasing interest in mindfulness in schools, how ought we think about, conceptualise, and critically reflect upon the promotion of mindfulness interventions in educational settings? If education involves developing the capacity to pay attention in a creative, interested and curious way, why is the introduction of mindfulness programmes into schools seen as problematic by some?

The broader interest in mindfulness training initiatives may be in part due to the psychosomatic symptoms of anxiety and stress owing to the accelerated pace of life under contemporary capitalism. In the case of immaterial labour, such as the workplace in service industries and the knowledge economy, the capacity for flexibility, innovation, adaptation, and mobility is increasingly sought. Similar capacities are valued and privileged in educational policy. At the same time, experiences of precariousness and uncertainty that stem from changes in working conditions are exploited to purportedly maximise efficiency in the workplace. The rise of the 'precariat' and an increasingly technicist vision underpinning educational systems are not the only features of contemporary life that may have contributed to an interest in mindfulness. Theorists like Bernard Stiegler, Franco Berardi and N. Katherine Hayles comment upon some of the unprecedented ways in which new technologies and media are impacting upon psychic life in general, and in particular upon what Hayles calls 'deep attention'. This is because of the ways in which attention is constantly solicited through a range of media, which in turn generates a permanent heightened state of anticipation and alertness. Understanding the rationale for introducing mindfulness into school settings involves understanding the broader set of experiences of students. However, mindfulness in schools can serve to obscure this context and the causes of the symptoms that such programmes seek to redress. In the second part of this essay, I examine some of the ways in which mindfulness has been used in corporate and military contexts, and indicate some of the dangers of a performative, measurable, outcome driven and narrow conception of mindfulness that is divorced from ethical 
considerations and from context. The tendency to utilise the language of evidence for the 'effectiveness' of mindfulness is appraised, in particular when such claims are invoked in order to garner epistemic credibility. I suggest that the well-meaning efforts to secularise mindfulness, provide scientific evidence for its effectiveness, and introduce it to wider publics may have served to impoverish the rich contribution that practices of mindfulness, situated within a broader ethical framework, can make to human lives, and arguably contribute to the educational endeavour. For example, the emphasis on transforming inner conditions of students' lives can lead to the neglect of outer conditions, such as structural inequality, or unhealthy and exploitative work practices. This can result in practices that privilege individual wellbeing over compassion and concern for the happiness of others, providing a buffer against loving attention to the world and others, even if, as Oren Ergas $(2014,2013)$ argues that this is at odds with the expansive ethical vision underpinning the work of Jon Kabat-Zinn (1991, 1994, 2011) who has been so influential in the 'mindfulness movement'.

In the final section, I ask how mindfulness in educational settings might come to be viewed in a different light if we reflect upon the ways in which school environments and curricula could promote mindfulness, awareness, sensitive inquiry, and contemplative practices through the day, rather than offering it as a discrete intervention focused on the self. Mindfulness is not a practice that is foreign to education, so a more mindful approach to education may restore the idea that education ought to be in service of life. Likewise, a more holistic approach to education could invite a more expansive vision of curricular subjects and a more attenuated understanding of human embodied subjectivities. In terms of the curriculum, this could support coming to understand through experiencing the ways in which different subjects and pedagogical practices express different material potentialities, relational qualities, and sensibilities, as William James (2003) suggests in his Essays in Radical Empiricism. (See Ergas, this issue, for a detailed examination of James' concept of attention.) Practices of education that involve mindfulness could support this deepening of experience and a slower more process oriented approach that helps to open the self to the world and to itself.

\section{DIAGNOSIS: THE COLLAPSE OF ATTENTION}

In order to situate debates about mindfulness in schools, I wish first to examine the unprecedented ways in which attention has become both a scarce resource and a commodity. While it could be argued that humans have always had difficulty in paying attention, the emergence of new technologies has led to a 'phase shift' in the way in which humans interface with technological artefacts. This is of particular concern in the case of children and young people and research into the implications of this for human development is only in its infancy. A central feature of mental life, attention is increasingly experienced in a disjointed fashion due to the ways in which it is constantly solicited. In his polemical book Precarious Rhapsodies, Franco Berardi offers a pessimistic diagnosis of the evolution of psychic, 
affective and sensible life under capitalism. He argues that the acceleration and intensification of information transmission is leading to an overload of the senses and an experience of present time that is increasingly fragmented and discontinuous. He describes this as a mutation of capitalism, arguing that capitalism now seeks to target directly the sphere of psychic life. The consequences of this shift differ depending on one's position in the economic and social field. Such an experience is qualitatively different to that described by Marx and Engels in their analysis of workers' experiences of alienation through physical labour. Hardt and Negri (2001), in their creative interpretation of Marx, describe this colonisation of psychic and affective life as the real subsumption of Capital.

Examining the broader context of psycho-technologies and marketing, Berardi describes what he calls the political economy of attention. He calls it a 'political economy' because of the ways in which capital operates directly upon the psyche through the colonisation of the psycho-sphere, that is, it targets lived experience and the formation of subjectivities. This is particularly evident in the domain of attention. Capitalism through the constant solicitation of attention through a range of media, technological tools, and marketing strategies is connected to the brain and the nervous system. He believes that 'to understand the crisis of the new economy, it is necessary to begin from the psychic experience of the virtual class' (2009, p. 38), suggesting that the info-sphere, the 'interface between the media system and the mind that receives the signals' (p. 39) is asymmetrically structured because 'the universe of receivers, human brains of real people made of flesh, fragile and sensual organs, is not formatted according to the same standard as the system of digital transmitters' (p. 39). The consequence of this, he suggests, is panic, depression, attention-disturbance, hyper-activity, solitude, existential misery, anxiety, and so on. For Berardi, this series of pathological symptoms is a function of the accelerated digital and machinic time of contemporary life in which subjectivity is becoming increasingly dispersed. Humans, including children and young people, undergo experiences of information overload as their attention is ceaselessly solicited from multiple sources. He calls this 'attentive stress' and argues that such constant appeals for attention reduce the time permitted for affectivity, sensibility, and thinking. It becomes more and more difficult to accede to the simple experience of being an embodied subject with its own organic temporality and rhythms of existence. Narrowing the gap between stimulus and response creates the kind of being who does not and cannot reflect, whose experience is thinned, and who reacts rather than responds.

Philosophers like N. Katherine Hayles, Bernard Stiegler and Franco Berardi who are interested in the emergence of new forms of cognitive and affective labour and in the relationships between technics and humans are not technophobes. They do not appeal to a nostalgic time before digital technology, but they do want to show some of the potential implications of the interface between the human organism and emergent infotechnologies. Some of their reflections are of particular interest to educators. Hayles distinguishes between hyper-attention and deep attention. She states that 'hyper reading, which includes skimming, scanning, fragmenting and 
juxtaposing texts, is a strategic response to an information-intensive environment' adding that it correlates with 'hyper attention, a cognitive mode that has a low threshold for boredom, alternates flexibly between different information streams, and prefers a high level of stimulation' (2012, p. 12). Deep attention, on the other hand, can maintain a single focus and has a high threshold for boredom. She does not wish to argue that one kind of reading is preferable to the other - each has its strengths and benefits - and hyperattention is useful in those information-intensive environments which many children and students now navigate from birth. However, 'deep attention is a precious social achievement that took centuries even millennia to cultivate $[\ldots]$ ' (p. 99), and the increasingly rapid response times encouraged through activities that promote hyper attention generate a dispersed and distracted subjectivity that constantly checks emails, social media, surfs the web, plays computer based games, and so forth, but finds it increasingly difficult to simply 'pay attention'.

The danger of losing the capacity for deep attention and the destruction of the 'juvenile psychic apparatus' is also a worry for Bernard Stiegler. If attention is understood in the context of the attention economy, in particular in relation to the objects of our attention, it may help us to understand why New Wave film director Jean-Luc Godard thought that people should be paid for watching television: they are giving their attention and thus their time and their lives to an apparatus that captures their consciousness. Marketing mechanisms are devised to solicit and capture attention, and the capacity to sustain attention is destroyed through the constant short-circuiting that forbids the laying hold of memory which in turn precludes the focus, awareness and concentration required for the digestion and integration of experience. Attention deficit is not, then, simply a psychological disorder but a feature of contemporary life when the organism develops in an info-saturated environment. The pharmacological relationship with attention deficit disorder diagnosis is well documented.

In respect of our topic of mindfulness in schools, in particular in relation to attention, it is difficult to say what the cause of the current interest in, or perceived need for, mindfulness training, might be. It could be due to the rise in attention-related psychopathologies sketched by Berardi (2009), Stiegler $(2010,2013)$ and others. It could be because technological innovation, in particular fMRI scanning in the field of neuroscience, finally showed evidence of neuroplasticity through meditation whereby the data from these experiments provided empirical evidence for first person reports of experiential change. It might be because meditation, or mindfulness, became legitimated on the basis of credible scientific evidence through its incorporation into health institutional structures. Or it may be due to a confluence of factors. Whatever the case may be, it is interesting to reflect upon the ways in which mindfulness and the arguments for its utility, in particular in corporate and educational contexts, tend to be framed without explicit reference to, or serious consideration of, the implications of the colonisation of the 'attention economy' and the motivations that draw people and organisations into engaging with mindfulness programmes, including Mindfulness Based Stress Reduction (MBSR) and Mindfulness Based Cognitive 
Therapy (MBCT). There is insufficient examination of 'outer' conditions, the causes of the collapse of the capacity for attention and the implications of this for lived experience. Finally, 'capitalist spirituality' extends the market mechanism and economic rationality into the domain of human beliefs, desire, subjective life and lived experience.

\section{AN APPARATUS OF CAPTURE?}

Practices of mindfulness are seen to be helpful in responding to and creatively resisting some of the consequences of the prevalence of attention deficit in contemporary life, as outlined by Stiegler and Berardi. However, practices of mindfulness may also be re-territorialised, to use a trope of Deleuze and Guattari (1987), or co-opted into existing regimes in such a way that the revolutionary, transformative or liberatory potentials of such practices are diminished. Deleuze and Guattari (1987) describe mechanisms to tame these potentials by using the language of 'apparatus of capture'. This concept is useful when reflecting upon 'technical' and instrumental approaches to attention formation. Neuroscientists and cognitive scientists have been particularly interested in researching how meditative practice brings about the 're-wiring' of the brain's circuitry, in part because this shows evidence of neuro-plasticity and the ways in which experience shapes physiological processes. Other related fields of new research attentive to the problematic implications of human engagement with new technology is being undertaken in areas like cyber-psychology that seek to examine the effects on children and young people of prolonged periods of interfacing with digital media. One perhaps unintended effect of 'the turn within', be it through the rise of the self-help industry, cognitive behavioural techniques, or even mindfulness programmes, has meant that those more radical or systemic critiques that attend to and evaluate the outer conditions that shape people's inner and psychic lives are given less and less weight. Yet, approaches to 'mindfulness' that teach people how to 'surf' their uncertainties and anxieties without seeking to understand or become aware of the causes of suffering are at odds with the Buddhist origins of these practices which seek to develop the understanding of the causes of suffering and to cultivate compassion, ethical skilfulness, judgement, right action, and right view. In corporate mindfulness in particular, the focus is explicitly on managing 'inner conditions' without critical interrogation of the workplace. In this respect, mindfulness techniques are seen as useful tools in alleviating or mitigating those very symptoms of stress, anxiety, depression that have, as argued above, have increased in recent times.

James Reveley (2014) addresses the burgeoning interest in mindfulness training in light of advances in research in neuro-plasticity. He asks whether we are 'pathology-proofing' children or empowering them, saying that typically such programmes are presented as methods for training which enable self-regulation, attentional skills, stress reduction and supportive aids for general wellbeing and they tend to be offered without further investigation of the causes and conditions of stress, anxiety or a broader symptomatology. In short, there is little critical investigation of the reasons 
that bring many people to mindfulness, often through Mindfulness Based Stress Reducation (MBSR) courses. Reveley rightly, in my view, situates these programmes within the context of 'digital capitalism and the social pathologies it generates' (2014, p. 3). He argues that Jon Kabat-Zinn's transposition of mindfulness from Buddhism into the scientific (and secularized) domain of 'medico-psychological discourse' has inadvertently supported the image of mindfulness as a form of neuro-enhancement, although he also acknowledges Kabat-Zinn's own concerns about and analysis of an 'entire society [suffering] from attention deficit disorder' (Kabat-Zinn quoted in Reveley, 2014, p. 4). Bluntly put, Reveley believes that mindfulness serves as a vital instrument for pathology-proofing young people today, constituting, in this respect, a societal safety-valve. I think that in many respects Reveley's analysis is correct, nonetheless I wish to keep an open-mind in respect of the potential benefits of such a 'band-aid', even if it allows simply for marginally different and more open experiences of the relation to oneself and the world. Indeed, such an experience may have effects not anticipated by the original rationale for the introduction of such programmes, or by the person engaging in such practices. For instance, there is evidence (Condon et al., 2013) that engagement in MBSR courses increases compassionate responses to suffering. In the last section, I will explore the question of how mindfulness in schools might open up richer and more creative possibilities of experience in greater detail.

If we stay with our critical evaluation for the moment, it should be noted that mindfulness is a commodity sold to and through a variety of institutional settings, rather than the practice of offering teachings as a gift and students respond with generosity or dana as originally envisioned and practiced in Buddhism. The commercial dimension to the introduction of mindfulness in schools is important if we wish to critically reflect upon the diversity of reasons for the promotion of and justification for such programmes. Nicholas Rose's comments, both on the way in which life has come to be seen as a project and how one's identity is now seen as something to be managed, shed some light on this. He believes that 'characteristic of advanced democracies [is that life as a project] is constitutively linked to the rise of a breed of new spiritual directors, "engineers of the human soul", adding '[a]lthough our subjectivity might appear our most intimate sphere of experience, its contemporary intensification as a political and ethical value is intrinsically correlated with the growth of expert languages, which enable us to render our relations with our selves and others into words and into thought, [...] with expert techniques, which promise to allow us to transform ourselves in the direction of happiness and fulfilment' (1996, p. 157). Likewise, Nigel Thrift describes New Age training in corporate environments, noting that executives from 'the Bank of England, British Gas, Ernst and Whinney, Mars and Legal and General' (2005, p. 42) have all been given lessons in how to do the Whirling Dervish dance. It should not be forgotten that such initiatives are devised with the intent of developing creativity, efficiency, innovation and ultimately profitability. Yet, this also reveals the underside of the intensification of capital and its toll on workers at all levels of organisations. Thrift writes 'what is interesting about current 
management literature, from the popular to the academic, is the amount of space given over to the stresses and strains of being a member of the new economy: sometimes it seems that all that managers have found are ways to oppress themselves as well as their workers', quoting John Perry Barlow "“How thin can I spread myself before I am no longer 'there'?"' (p. 152). In other words, the variety of self-help interventions available to workers is not effective because the conditions in which they work militate against alleviation of the symptoms through such interventions.

Ed Halliwell, co-director of the Mindfulness Initiative supporting the UK All-Parliamentary Inquiry Group on Mindfulness, is cognisant of concerns about the decontextualised operationalisation of mindfulness, the criticisms about the lack of ethical framework in mindfulness initiatives, and the lack of regulation of mindfulness training. He writes that 'mindfulness trains compassion-bringing kindness to experience is what distinguishes this from the concentration and balance of the unfeeling sniper' (Halliwell, 2014) and argues that 'part of the challenge for the field, and for the Parliamentary inquiry, is to meet the openness to workplace mindfulness in artful ways that neither collude with mindlessness in corporate cultures nor alienate those working within them' (Halliwell, 2014).

The effort to introduce mindfulness to the military underlines the ethical complexity of this movement to introduce mindfulness to diverse groups. Elizabeth Stanley and Amishi Jha have been instrumental in developing a mindfulness programme for the military called Mindfulness-based Mind Fitness Training (MMFT, Stanley et al., 2011). Stanley (2014) details her motivation for initiating MMFT through her own experiences of mindfulness awareness practices. I quote from her essay at length,

My definition of warriors is inclusive: anyone who serves their communities in high stress contexts, including members of the military, law enforcement and other first-response organisations. As an academic who teaches and writes about international security, I believed that mindfulness and body-based self-regulation skills could help with the cognitive degradation (well-documented in empirical research) associated with military stress-inoculation training. I believe it might help troops regulate their ANS [autonomic nervous system] and thus function more effectively while deployed. In military circles, this is called the 'strategic corporal' concept, where an individual's choices or actions while deployed have tremendous effects on the nation's ability to achieve its strategic goals. I also believed it might shield troops - and their families - against health disorders and behavioural symptoms of the stress system after returning home (http:// www.inquiringmind.com/Articles/CultivatingMindOfWarrior.html).

The evidence that scientific research brings from studies with civilians suggested, they argue, that mindfulness training could 'optimise warrior performance by cultivating competencies critical for modern battlefield, such as improved self-regulation, better attentional skills, and enhanced situational awareness' (Stanley and Jha, 2009, p. 148). There is no consideration of 
ahimsa, the Sanskrit term for the Buddhist precept of non-harming or nonviolence that permeates ethics (sila in Sanskrit), other than the invocation of mindfulness' contribution to harm reduction in that there will be a decreased likelihood that the wrong target will be accidentally killed if the capacity for self-regulation and so forth is developed. Hyland (this volume) offers a careful critique of the militarisation of mindfulness and of what have been called McMindfulness programmes (Purser, 2014; Purser and Loy, 2013).

\section{RETURNING TO THE ETHICAL ROOTS OF MINDFULNESS}

The original pragmatic and ethical effort to secularise Buddhist practices, initiated in order to help alleviate the suffering of those who might not otherwise engage with meditation within a more explicitly ethically-oriented wisdom tradition, was, I believe, of real value, and I acknowledge the continued importance of embedding MBSR and MBCT in health organisations. However, an unintended consequence of providing the scientific evidence to demonstrate the effectiveness of mindfulness as an intervention is the impoverishment of the ways in which the practice is communicated and its value explained, in particular when it is instrumentalised as a technique primarily focused on the self rather than as part of an ethical practice and way of life. This is not universally the case and there are a number of thoughtful pieces on mindfulness in education that articulate a more holistic and rich understanding of the practice. For example, the Clinical Handbook of Mindfulness offers a set of considered reflections that show the importance of depth of practice and ethical integrity. Indeed, mind and heart are the same words in a number of Asian languages, and the translation of mindfulness into heartfulness communicates the compassionate roots and orientation of the practice.

In Kabat-Zinn's foreword to that book, he reiterates his belief that mindfulness has universal value and he writes of 'our intrinsic capacity to embody the full potential of our species [...] for wakefulness, clarity and wisdom' (2009, p. xxvi). Rather than the language of cognition, he prefers awareness, and he emphasises that mindfulness is only one factor in the Noble Eightfold Path, the meaning of which continues to be debated. He explains that his definition 'paying attention, in a particular way, on purpose, in the present moment and non-judgementally' is an operational one, and 'it leaves the full dimensionality and impact of mindfulness or mindful awareness implicit and available for ongoing inquiry and investigation [...]' (p. xxvii). Mindfulness is aim, method, practice and outcome, and its non-striving orientation is not 'performative' or outcome-driven but rather emphasises 'nowhere to go, nothing to do and nothing to attain' (p. xxix). The embodied, living, and vital presence of the mindfulness teacher as practitioner, and the sensitivity of the meditator and teacher to the complexity and richness of first-person experience ought not, he argues, be supplanted by a 'customary manualised approach to the delivery of psychological interventions' ( $p$. xxxii). A further difficulty faced by those who wish to help others share the experience of mindful living is, as we have seen, that 'conventional 
scientific methods may not easily lend themselves to a refined exploration of mindfulness' (Grossman and Van Dam, 2011, p. 220).

It is with this in mind that I would like to explore a more expansive understanding of mindfulness as part of a holistic practice, an ethics and a philosophy, rather than simply a tool or technique. I do so in order to invite further reflection upon experience, embodied subjectivity, context, sensibility and ethics in education. At present, mindfulness is in danger of being co-opted into the 'evidence-based', 'what works' agenda that has proven so problematic for many of us working in educational settings, as, by prioritising performative indicators and valuing only that which can be measured, risks instrumentalising what is a rich existential and ethical practice and using inappropriate forms of evaluation (Van Damm et al., 2009). Terry Hyland (this issue) examines this question in some detail. Such a practice that allows us to explore what it means to be a sensible, cognising, moving, perceiving, embodied, ethical being can support the holistic education of the young. Indeed, Kabat-Zinn writes, 'Mindfulness can only be understood from the inside out. It is not one more cognitivebehavioural technique to be deployed in a behaviour change paradigm but a way of being and a way of seeing that has profound implications for understanding our own minds and bodies, and for living life as if it really mattered' (2011, p. 284).

\section{CREATING LITTLE SPACES IN EVERYDAY LIFE: ATTENTION AND EDUCATION}

Despite the detailed critiques of mindfulness interventions that I have outlined above, mindfulness might also be described as a Trojan Horse that needed to be disguised in order to be permitted entry into those institutions and organisations that would otherwise be wary of anything that might be viewed as ideological or religious, or those institutions that accept only interventions premised upon experimental scientific evidence. Despite the reservations that I have outlined about the dangers of reducing mindfulness to a set of techniques or prescriptions that can be operationalised, I remain positive about the introduction of mindfulness into schools and supportive of creative ways of developing institutional cultures that cultivate mindfulness in students and teachers. This is because such practices develop the capacity for creative and deep attention, which helps to support greater clarity, non-reactivity and ethical sensitivity, as well a richer experience of life. Even if the critics are right that the translation of these practices into secularised, operational techniques fail to explore and value the ethical and wisdom traditions of which mindfulness is but one element, when it comes to schools, it should be remembered that mindfulness involves, as critics acknowledge, simply beginner practices that allow for a taste of some elements of complex and rich wisdom traditions. Rather than being concerned about fidelity to such wisdom traditions, the more important question may be: do students feel that their encounters with mindfulness help them to live? Do such encounters enrich the quality of their lives and encourage compassionate relationships with others? If the response is that they do, 
this also raises a set of further questions about responsibility for the outer conditions of students' lives, in particular if these damage their wellbeing. These could include a careful examination of the conditions of schooling and the institutions in which children spend so much time.

Taking mindfulness seriously would also bring us to ask what role institutional and school cultures have in creating problems experienced by many young people, the problems that mindfulness seeks to retrospectively address. Do schools themselves provide supportive environments for mindful existences and experiences? Do practices, institutional structures and objectives and aims in education create stress, comparison or anxiety? Do schools offer the opportunity for student voice and participation? What is the risk that mindfulness programmes will simply be used in order to 'pathology-proof' students, inoculating them against stress, and paralysing opportunities for critique and resistance whilst refusing to examine the role of schools and educational policy in creating some of the suffering that mindfulness interventions are supposed to alleviate? However, if schools genuinely recognise and acknowledge the benefits of mindfulness, including the joys of attentive awareness and the existence of the suffering of students, then this may lead to a more radical critique of schooling. This could invite careful examination of the responsibility of educational policymakers and of schools themselves in cultivating cultures and curricula to create 'outer conditions' that are more supportive to students and teachers in their efforts to develop more subtle, nuanced, open practices of attention and compassionate awareness. I suggest that it is insufficient, and even unethical, to focus solely on 'inner conditions' if such changes to 'outer conditions' can be made. Indeed, arguably it is near futile to persist in 'addon' interventions if broader systemic, cultural and organisational changes do not accompany efforts to develop mindfulness amongst students. Even simple questions like the following are important in this respect: do students and teachers feel as though the curriculum is rushed through or alien to their lives? Are students and teachers subjected to audit cultures premised upon control that emphasise outcomes and performativity rather than giving them the space to be, reflect and find their own voices?

Mindfulness is concerned with 'non-doing' and with 'how things are', says Jon Kabat-Zinn. So too, teaching mindfulness means responding to 'where people are at', helping them to bring the quality of attention into their lives through practices that are most appropriate to their lives and situations. Asking the question, 'to what do I ordinarily give my attention?' helps us to understand what we value in our lives, and perhaps to make us more aware that our attention is, in fact, oriented in ways that are at odds with our values or ideals, or even how the quality of our attention, or objects of our attention, militate against developing a deeper awareness of, and attunement to, the nature of our experience. Part of the practice of mindfulness involves 'an appeal to the subject's quality of mindfulness as the application of an objective stance in the face of his own subjectivity' (Ergas, 2014, p. 64). This, again paradoxically, cultivates a richer relationship to one's own experience as one investigates it and inquires into it with compassionate curiosity, rather than living out one's habits through repetitive and broadly 
unconscious patterns of behaviour or engaging inadvertently in compulsive thinking or 'mind-wandering' (Ergas, 2013, p. 276).

Deploying more heterodox methods inspired by mindfulness practices rooted in the Buddhist tradition, that are both integrated into the curriculum and school experience, and appropriate to the needs of children and young people may be what will be of most service in schools. Although arguments are often made against permeated approaches because of its attention to experience, an on-going permeated approach to mindfulness in schools may be more helpful than simply discrete interventions, even if initial training in mindfulness may be required for students. Here we return to the theme with which this essay began: paying attention. Although attention is only one element of the Noble Eightfold Path, developing the capacity for creative attention in schools may open up different potentials for sensibility, care, and richness of experience simply because the temporality and openness of the act of attention interrupts habitual associations and invites a spaciousness and non-reactivity into experience. Teaching is seldom served well by generic and formulaic methodologies or by pedagogies divorced from philosophical and ethical principles, and so it may be that the problem lies only in those 'ready-made' or 'generic' approaches to mindfulness teaching that are not attuned to the dynamics and potentials of a singular class, that seek prescribed outcomes, that seek to be 'neutral' rather than honest about the ethical and spiritual origins of the practice, and that fail to intuit those unpredictable moments that can invite insight and transformation. Where mindfulness techniques meet creative pedagogy, contemplative inquiry and the kind of unselfing that education involves through the way that it brings our careful attention to something other than ourselves, this may allow for mutual transformation of all of these practices. Minimalist, exploratory, philosophical, creative, sensitive and speculative approaches to mindfulness are also indicative of good teaching, and it is this that may be of most benefit in thinking about how schools and classrooms are to become more mindful. If policy-makers and experts are serious about the value of mindfulness, it cannot be 'velcroed' onto existing curricula and institutions, especially if current pedagogical practice or institutional cultures undermine the development of the capacity for mindfulness, attention, awareness and compassion.

It is at this point that I will bring together the wisdom and philosophical traditions of East and West by reflecting upon the relationship between attention, unselfing and education. The position I map is, in certain respects, rather different from that of Ergas (this issue) in respect of the value placed on the 'out there'. Whilst thus far in this essay, the discussion of practices of attention has been rooted in approaches to mindfulness with Buddhist origins, attention was also the theme that lay at the heart of Simone Weil's philosophy, a thinker influenced by religious and philosophical thought from Greece to India, who explicitly related attention to study in her essay 'Reflection on the Right Use of School Studies with a View to the Love of God' (in Weil, 1959). She saw developing the habit of attention as an essential ethical practice and as such for her it lay at the heart of the pedagogical endeavour. Just as importantly in the context of this essay is the 
way in which throughout her writings she understood attention in renunciative terms, distinguishing it from an exercise of the will, concentration or strained muscular effort, and describing it instead as a kind of waiting without expectation that involves renouncing oneself to make space for the other to which one attends. Her metaphors presenting attention as a kind of seeing or reading find their origins in part in the Platonic image of the sun that shines impartially on all existents, regardless of whether they are good or evil. Attention, or love, involves really looking, really seeing. In this story, this exercise of 'reading' is a kind of waiting and accepting. Like vision, attention needs an intimate distance. One cannot see when one is too close - one loses oneself in the object of one's attention, over-identifying or fusing with it, just as one cannot see when one is too far. Just as the sun's rays illuminate without discrimination, to accept that the other $i s$, and to accept that other as it, he or she is, without wanting to change that other, provides the substance for a relation of attention. She writes, 'attention consists of suspending our thought, leaving it detached, empty, and ready to be penetrated by the object' $(1959$, p. 111). Although it initially requires persistence, striving and effort to maintain the discipline, it gradually comes to fill the mind. This is not an attitude of cold objectivity but rather it illuminates whatever is the object of attention with love-indeed attention is a form of love for Weil. She says, 'Attention consists of suspending one's thought, leaving it detached, empty and ready to be penetrated by the object' (1959, p. 112). Through an apprenticeship in paying attention, waiting without expectation, and accepting 'what is' and 'how it is', one begins to purify oneself of those projections, fantasies, and reactive strivings that typify much human existence. Iris Murdoch (2001, p. 52) calls the human tendency toward possession and narcissism, the 'fat relentless ego'.

It seems peculiar to espouse such the renunciatory ethic of kenosis, in particular when contemporary educational discourses so often emphasise capabilities, flourishing and self-development, but in a confessional and correctional culture, it might be wise to resist the temptation to focus solely on the self and mindfulness discourses are often positioned as a kind of 'self-help'. Weil thinks of attention as always attending to something or something other. It is relational, opening us to what is not us. One waits, one attends to something or someone that is not oneself. The creation of distance, a loving distance, is at the heart of the relation of attention and helps one to come to 'see things as they are'. This renunciative movement is what she calls 'decreation' (Weil, 1956, 2002). Attention involves the greatest of efforts, but a 'negative effort' (1959, p. 110). When we reflect upon the role of attention in education, it can be helpful to reflect upon those contemplative, educational spaces that cultivate the conditions for forms of intimate or loving distances that involve this kind of 'decreation', contemplation or waiting that Weil sees as creative attention. Attention is, in her view, both the substance of the ethical relation in its higher form, and proto-ethical as one cultivates and develops practices of paying attention. So, is it possible to develop contemplative pedagogical practices that support deep attention and creative attention? 
Keeping in mind Weil's writings on renunciatory ethics, studying and the importance of developing the habit of attention might help mindfulness programmes in schools to sustain a sense of openness in practice that remembers to also turn outward to beings other than oneself, helping to de-centre the self, and intensifying contact with reality through the practice of attending to rather than getting mired in the projections and fantasies of the self. Even one's own body, sensations and breath can be attended to in an 'impersonal' way that paradoxically opens up experience in a way that feels liberating. Fortunately, the practice of paying attention is also, oftentimes, a joyful one, even if it runs counter to fundamental narcissistic human tendencies to imagine and possess. At a minimum, mindfulness practices and practices of attention and contemplation that meet with creative pedagogies can support lives that are a little less reactive, more creatively responsive to 'what is', more capable of being reflective, appreciative and grateful for simply existing, and curious, and more interested in the nature of their experience and in the world in which they live. Oddly, practices that support giving one's attention can provide a useful counter-balance to those therapeutic practices and psychological discourses that centre on the self. Given the emphasis on outcomes and 'what works' in educational research more broadly and in mindfulness practice in particular, it is important to underline the paradox of the practice: maintaining the discipline of a practice, whilst not striving for specific outcomes and not being wilful in one's efforts may be more likely to support transformation in someone's life, just as not focusing on learning outcomes in pedagogy, may invite approaches that are more mindful and contemplative, allowing for the kind of deep attention and experiential engagement that supports learning.

Of course, many of the approaches to mindfulness in schools chime with good teaching, in particular those holistic approaches that seek to deepen experiential inquiry and investigation that are motivated by what Arthur Zajonc (2009) calls 'an epistemology of love'. Curricula framed as MBSR for children often offer more expansive, philosophical and creative methodologies than might be expected. Even mindfulness practices that stay at the level of what Richard Shusterman (2008) calls somaesthetic practices, such as noticing the rise and fall of one's breath without explicit ethical exploration, may allow for 'breathing spaces' in schools and an ethos that values this spaciousness. Saltzman and Goldin's creation of an MBSR curriculum invites philosophical speculation from children 'What does dead feel like?' They answered, 'like a swan', 'like an angel', or 'like floating' (2008, p. 141). Like adult approaches to mindfulness that begin with a bodyscan, awareness of bodily experience can be experienced through Seaweed Practice, an exercise that invites children to slowly move their bodies like seaweed floating under water. Another example is the Thought-Parade, an exercise of imagining one's thoughts are walking by. This was designed to support the practice of observing one's thoughts without identifying with them or reacting to them. Children are even asked to do 'Thoreau' walks as a form of walking meditation. Finding ways for children to inquire into and articulate their experience can be difficult, so the idea of 'funny mind' is mobilised to help children remember that thoughts are just thoughts and they 
pop in and out of our heads. And thinking of someone you love and sending love to that person or being is a way of translating the loving-kindness meditation into the life of the child.

As Hooker and Fodor (2008) also point out, often children are closer to being naturally mindful in their everyday lives than adults so they offer different kinds of exercises to encourage mindfulness like drawing an object in greater and greater detail, which involves a practice of deep looking. The difficulty with framing mindfulness in schools in terms of stress reduction is that it fails to capture the pedagogical and broader experiential potentials of the practice. What Simone Weil's philosophy of attention shares with approaches to teaching mindfulness is the paradoxical sense that de-centring the self through different practices of attention can invite a richer sense of one's own experience, a deeper knowledge of the world, and compassion for others. Perhaps it might be wise to be less worried about the authenticity of secularised versions of mindfulness, and more concerned by how we can make schools more mindful places which marry the most creative pedagogies with the insights of mindful practice and creative practices of attention, helping us to reflect once more on the existential questions that philosophers of education have posed for so long: what do we hope for from education? What do we value in education? What are the ends of education, and how do our means support those ends? However, without the sense of a wider context and critical discourses about education and the attention economy, mindfulness practice in schools that is limited to brief interventions within a wider curriculum, or which takes place within school cultures that foster thoughtlessness and carelessness rather than mindfulness, may end up at best 'pathology-proofing' the young, rather than demonstrating real care for them.

Correspondence: Aislinn O’Donnell, Mary Immaculate College, University of Limerick, South Circular Road, Limerick, Co. Limerick, Ireland.

Email: Aislinn.odonnell@mic.ul.ie

\section{REFERENCES}

Berardi, F. (2009) Precarious Rhapsodies (London, Minor Compositions).

Condon, P., Desbordes, G., Miller, W.B. and DeSteno, D. (2013) Meditation Increases Compassionate Response to Suffering, Psychological Science, 24.10, pp. 2125-2127.

Deleuze, G. and Guattari, F. (1987) A Thousand Plateaus (Minneapolis, MN, University of Minnesota Press).

Ergas, O. (2013) Two Mind-Altering Curriculums: Contemplation, Mindfulness and the Educational Question 'Whether to Think or Not to Think', Journal of Tranformative Education, 11.4, pp. 275296

Ergas, O. (2014) Mindfulness in Education at the Intersection of Science, Religion and Healing, Critical Studies in Education, 55.1, pp. 58-72.

Grossman, P. and Van Dam, N.T. (2011) Mindfulness, By Any Other Name ... : Trials And Tribulations of Sati in Western Psychology and Science, Contemporary Buddhism, 12.1, pp. 219-239.

Halliwell, E. (2014) Mindfulness: Has it Been Hijacked by Business or Can it Change Lives, The Guardian, 25 July.

Hardt, M. and Negri, T. (2001) Empire (Cambridge, MA, Harvard University Press). 
Hayles, N. K. (2012) How We Think: Digital Media and Contemporary Technogenesis (Chicago, IL, University of Chicago Press).

Hooker, K. and Fodor, I. (2008) Teaching Mindfulness to Children, Gestalt Review, 12.1, pp. 75-91. James, W. (2003) Essays in Radical Empiricism (New York, Dover).

Kabat-Zinn, J. (1991) Full Catastrophe Living (New York, Delta Trade).

Kabat-Zinn, J. (1994) Wherever You Go, There You Are (New York, Piatkus Books).

Kabat-Zinn, J. (2009) Foreword in: F. Didonna (ed.) Clinical Handbook of Mindfulness (New York, Springer).

Kabat-Zinn, J. (2011) Some Reflections on the Origins of MBSR, Skillful Means, and the Trouble with Maps Contemporary Buddhism, 12.1, pp. 281-306.

Loy, D. and Purser, R. (2013) Beyond McMindfulness, Huffington Post 1 July.

Murdoch, I. (2001) The Sovereignty of Good (London, Routledge).

Purser, R. (2014) The Militarization of Mindfulness; Inquiring Mind, Spring. Available at: www.inquiringmind.com, accessed 1 February 2015.

Reveley, J. (2014) School-Based Mindfulness Training and the Economisation of Attention: A Stieglerian View, Educational Philosophy and Theory, May, pp. 1-18.

Rose, N. (1996) Inventing Our Selves: Psychology, Power and Personhood (Cambridge, Cambridge University Press).

Saltzman, A. and Goldin, P. (2008) Mindfulness-Based Stress Reduction for School-Age Children, in: L. Greco (ed.) Acceptance and Mindfulness Treatments for Children and Adolescents (Oakland, CA, New Harbinger).

Shusterman, R. (2008) Body Consciousness: A Philosophy of Mindfulness and Somaesthetics (New York, Cambridge University Press).

Stanley, E. (2014) Cultivating the Mind of a Warrior, Inquiring Mind, 30.2. Available at: $\mathrm{http}: / /$ www.inquiringmind.com/Articles/CultivatingMindOfWarrior.html

Stanley, E., Shaldach, J., Kiyonaga, A. and Jha, A. (2011) Mindfulness-based Mind Fitness Training: A Case Study of a High-Stress Predeployment Military Cohort, Cognitive and Behavioral Practice, pp. 566-576.

Stanley, E. and Jha, A. (2009) Mind Fitness: Improving Operational Effectiveness and Building Warrior Resilience, Joint Force Quarterly, 55.4, pp. 144-151.

Stiegler, B. (2010) Taking Care of Youth and the Generations (Palo Alto, CA, Stanford University Press).

Stiegler, B. (2013) What Makes Life Worth Living (Cambridge, Polity Press).

Thrift, N. (2005) Knowing Capitalism (London, Sage).

Van Dam, N., Earleywine, M. and Danoff-Burg, S. (2009) Differential Item Function Across Meditators and Non-Meditators on the Five-Facet Mindfulness Questionnaire, Personality and Individual Differences, 47.5, pp. 516-521.

Weil, S. (1956) The Notebooks of Simone Weil Volume 1 (London, Routledge).

Weil, S. (1959) Waiting on God (New York, Capricorn Books).

Weil, S. (2002) Gravity and Grace (London, Routledge).

Zajonc, A. (2009) Meditation as Contemplative Inquiry (Great Barrington, MA, Lindisfarne Books). 